MARKETING AND BRANDING
RESEARCH $\begin{gathered}\text { INDUSTRIAL } \\ \text { MANAGEMENT } \\ \text { INSTITUTE }\end{gathered}$

\title{
Data driven customer experience and the roadmap to deliver happiness
}

\author{
Ahmed Aly Shaban Abdelmoteleb ${ }^{1 *}$, Suzilawati Kamarudin ${ }^{1}$, Puteri N. E. Nohuddin ${ }^{2}$ \\ ${ }^{1}$ International Business School, Universiti Teknologi Malaysia, Kuala Lumpur, Malaysia \\ ${ }^{2}$ Institute of Visual Informatics, Universiti Kebangsaan Malaysia, Bangi, Malaysia
}

\begin{abstract}
Keywords:

Happiness, Customer

Satisfaction, Customer

Experience, Data

Driven Customer

Experience, Customer

Relationship

Management,

Correspondence:

aly_1980@hotmail.com

Happiness is a choice, in which individuals have the ability to create lasting and genuine happiness for themselves. They make choices and take actions to be happy, choosing what to wear, what to eat, whom to love, and where to work. It is very subjective to delimit whether our choices are good while others are not but all based on individual profound desire to be happy. In some related work, researchers have found a strong correlation between customer satisfaction, happiness, and organization performance. Many organizations have spent money and effort in innovating and implementing initiatives, which were focusing on increasing customers' satisfaction; however, customers are not happier today compared to what they were before. Therefore, the need for studying on mechanism of achieving customer happiness is crucial to ensure effectiveness and efficiency of customer service initiatives. In fact, it is important to identify factors that can elevate customer happiness and shift customers from comfort to happiness zone. This will motivate organizations to design products and services that can meet customer needs and exceed customer expectation in every touch point. In UAE, customers come from 202 countries with diverse cultures, religions, habits and ethnicity, which force government, semi-government and private sector to deliver services that not only meet but also exceed customer expectations. Accordingly, the paper will take you through the journey of UAE government for exceeding customer expectations starting from understanding drivers of happiness using a research framework that segment customers in different zones (Trust vs. Control \& Stand out vs. Fit in) until quantifying drivers to measure service happiness score.
\end{abstract}

(C)AIMI Journals

According to (Torrico, 2010), poor individuals or families mostly satisfied and happy with their old black and white television and more delighted with receiving ordinary services 
which might be dissatisfying for others. Understanding these factors can influence people happiness and can positively affect their evaluation for services or products; accordingly, it will increase organizations' profits.

For decades, customer satisfaction studies are the widely used tool to measure customer evaluation and feedback about services or products; it is also supporting companies' longterm plans to improve both sales and profits (Anderson, Fornell, \& Lehmann., 1994). Major researches have proven the correlation between customer's mood and how it can positively affect customer evaluation during the shopping experience (Swinyard, 1993), evaluating products (Isen, Nygren, Taylor, \& Dulin, 1996) and improving the overall customer satisfaction scores (Torrico, 2010).

Mentioned studies developed their theories with limited scope and limited products as well and in homogenous population, which is a limitation for using available results in other markets.

This paper focuses on how to segment UAE customers based on a simple model, classifying customers into four different zones (Trust vs. Control \& Stand out vs. Fit in) (Callebaut et al., 2011).

In this paper, we will identify key drivers for customer happiness that can influence customer-buying behavior, customer relationship management, and customer experience and how we can use it to map 360 degree of customer journey related to government services in United Arab Emirates.

\section{Customer Behavior}

Customer-buying behavior is a process, which consists of three stages, namely decision, purchase, and usage of the product. To understand different factors that can drive customerbuying behavior, it is important to know that many aspects, factors, and individualities derived from psychology influence the customers' shopping habits, purchasing behaviors, and the chosen brands. Purchasing decision and action is the outcome of factors including customer culture, customer social class, customer personality, and customer psychological factors (Rani, 2014).

Customer culture exists among group of individuals who share the same type of values based on mutual experience or shared traditions. Customer social class refers to the group of individuals that usually share homogeneous life and classified against each other according to social pyramid. Customer personality, which is the customer experience with life, involves age, occupation, economic situations, and daily lifestyle such as hobbies, activities, and personal interests. Customer psychological factors involve factors such as perception, motivations, knowledge and understanding, believes, habits and attitudes. According to Rani (2014), there are different roles within reference groups that can influence customer-buying behavior including the initiator (individual who suggest buying and purchasing service or product); the influencer (individual who have a unique point of view and his advice will change or influence buying or purchasing decision, this could be one from the group or could be from outside community such as artist, singer or a player); the decision maker (individual who will take the action to choose which product to buy; and the buyer (individual who will buy and use the service or product and will benefit from it through usage). 


\section{Customer Relationship Management (CRM)}

Customer relationship management is the strategy that focuses on creating supreme value for the company by identifying, attracting, retaining, and developing customers. To achieve effective and efficient customer value, a complete integration inside the organization is necessary between sales, marketing, customer relation, and the supply-chain functions.

By analyzing mentioned definition, it is clear that CRM systems make three things happen (Greenberg, 2001). These three things are building a single view of customers, including analytical and data tools; managing relationships with customer in a one and simple way, irrespective of the channel he is using; and roadmap to improve processes effectiveness and efficiency that can affect relationship with customer. Many CRM implementations fail or struggle to succeed. The main reason behind this is that current approaches being used to develop a CRM project are not correct, since the integration complementation between both technological and strategic CRM features are not done adequately (Chalmeta, 2006).

When it comes to reasons for failure of CRM strategy, it could be from any of the following roots (Strauss \& Frost, 2002):

Decision makers thought that CRM is a technological solution: CRM is not a new technology for doing things, it is the business behind it. It is only enabler for the business needs; the absence of management backing and support is another reason and this is usually caused by the lack of understanding the benefits CRM will bring to companies; it is not a customer centric organizations or lack of customer culture; failure may happen when there is no clear strategy or vision. It happens when company has unclear strategy and key performance indicators around CRM; also, failure may arise when company implements CRM without redefining related processes. As with other IT projects, redefining the business processes is necessary for accomplishing solid results; garbage in garbage out, when quality of information is low, the wrong conclusions will be developed by companies.

Following these, lack of change management is another reason: During implementing any comprehensive project, appropriate change management should be on place to direct and help culture of companies to achieve the right objectives; and, lack of engagement with end users specially during designing CRM framework and solution immediately lead and increase the risk of developing a solution with challenges than solution with benefiting companies.

\section{Customer Experience (CE)}

The secret receipt behind ideal customer experience is not the multiplicity of options and bundles of the product or service, for instance, Microsoft products are packed with features and options that meet IT professionals' needs and they consider it as positive experience while many home individual users choose Apple's products which offers options and features. Apple's customer experience starts well before the customer turn it on (Meyer \& Schwager, 2007).

While interviewing senior business leaders in a related study, 85 percent agreed that price, service time, and waiting time is no longer the differentiator in building comprehensive customer service strategy (Shaw \& Ivens, 2002). The new differentiator today is customer experience. One of the considerable definitions of customer experience include that, the customer experience starts with customer's interactions with the product, or its company, 
which generate a reaction. This personal experience reflects the customer's involvement at five various stages, namely rational experience, emotional experience, sensorial experience, physical experience, and spiritual experience (Gentile, Spiller, \& Noci, 2007).

Figure 1 presents the conceptual model of customer experience creation (Verhoef et al., 2009).

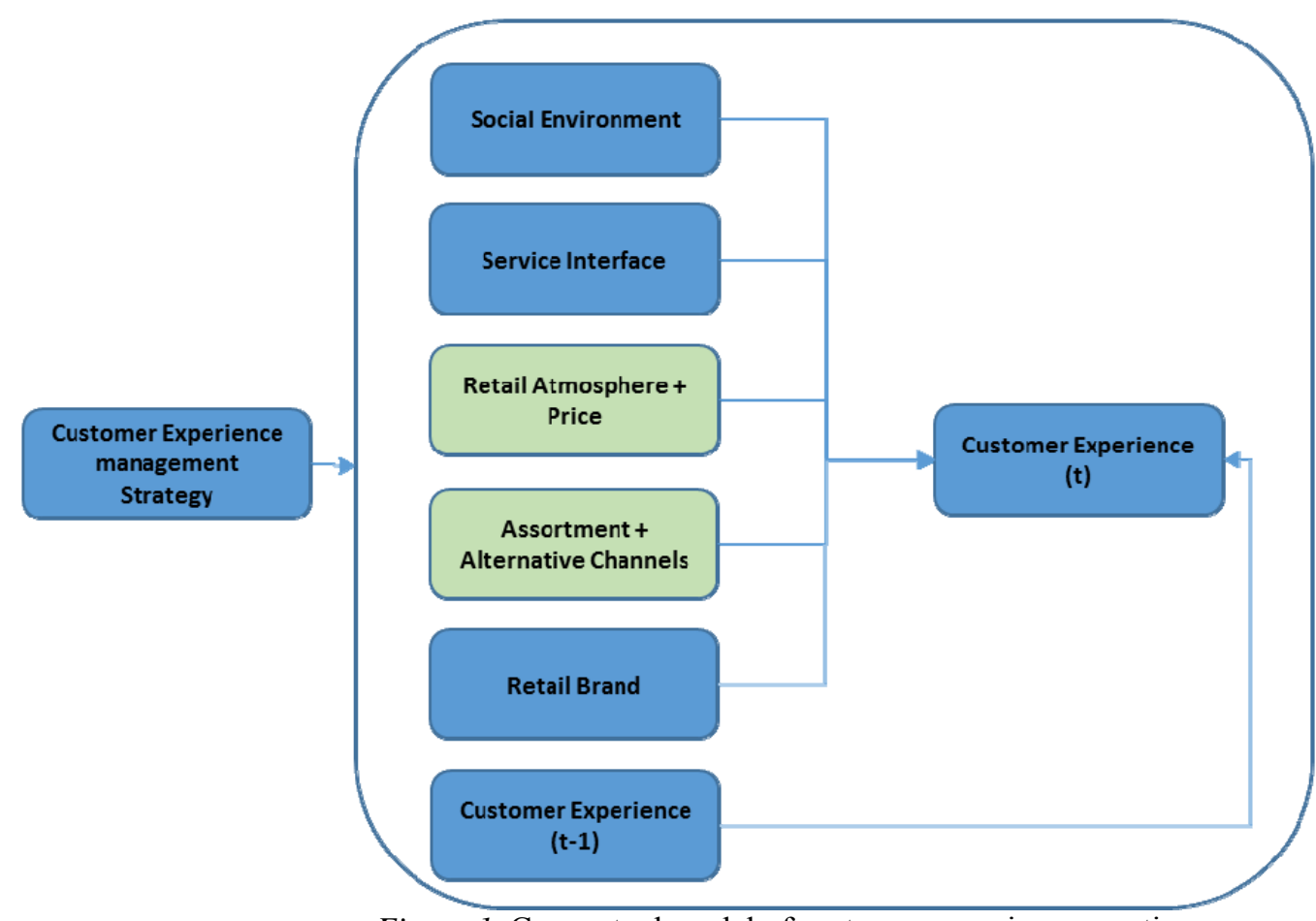

Figure 1. Conceptual model of customer experience creation

\section{Social Environment}

Either customers can affect one another directly or indirectly it is all about how much influence one have on another (Verhoef et al., 2009). For example, being close to others can generate feeling of anxiety. Eye contact between strangers may be negatively perceived and one's appearance may be perceived as threatening; this could be based on culture or ethnicity habits (Verhoef, Neslin, \& Vroomen, 2007).

\section{Self-Service Technologies}

Nowadays, customers mostly prefer the technology interface. Technology-based service delivery systems become an integral part of shopping and hence, are critical to observe in terms of their impact on customer experience to know whether it really adds value to the experience or it eliminates the human part of the experience. The demonstration of selfservice technology in retailing is proved by using the new shopping mode through either using the mobile applications or the online shopping. It has also proved using several technology-based methods within the day-to-day shopping atmosphere such as self-service counters that allow customers to checkout without agents help, and kiosks for bills inquiry and payment (Verhoef et al., 2009). 


\section{Branding and Customer Experience}

Customers' brand perceptions may affect their customer experience. Recent research has begun to investigate new aspects of this relationship. It is found that the type of brand and consumers' perceptions of the brand can influence their behavior. For example, consumers primed to think of Apple behave more creatively than consumers primed to think of IBM (Verhoef et al., 2009).

It is also important to consider the reinforcing effects of the customer's experience and the brand over time. The interaction effect between the product and the customer's experience can be from one direction to another and can be bi-directional. This can be seen clearly in many brands in both positive and negative ways (Verhoef et al., 2009).

\section{Customer Experience Dynamics (t-1)}

Today's customer experience can be impacted by yesterday's experience and other historical experience, which change and grow over time through product search, selection and purchase, usage, and after-sales service in case of any challenge during the usage (Verhoef et al., 2009). It may also involve multiple retail channels and repeated experiences within a channel and again this might have or build consequently a positive perception or negative one.

\section{Customer Experience Management Strategy}

Customer experience management is a vendor's strategy to engineer the customer's experience in such a way as to create value to both the customer and the firm. Working with customer experience strategy means that your customer is on the center of your business and means that your organization is customer centric organization. There is a need to understand how marketing and management strategies will optimize the brand customer experience interaction and what strategies will have the most positive influence on - and financial returns from - customer experience over time (Verhoef et al., 2009).

\section{Customer Happiness}

Happiness can be described as a person feeling very good, enjoying the moments of life, and having the wonderful state of both mental and physical health, while feeling unhappy is basically feeling bad toward life and toward state of mind. One of the clear definition for happiness is the emotional state where it is linked to sudden mood changes (Vermunt, Spaans, \& Zorge, 1989). Hence, happiness is the desire for well-being and how to avoid suffering that arguably motivates all behavior (Dodds \& Danforth, 2009).

Across different cultures, customers regularly rank happiness as what they want most in life, what they miss and what they would like to have (Dodds \& Danforth, 2009) and many countries have introduced methods for defining and measuring happiness to reflect state of well-being. Bhutan introduced Bhutan's National Happiness Index to measure people's happiness and in a way, they link it to services to measure happiness with the services offered to its citizens. This approach is not new; Bentham's hedonistic calculus and John Stuart Mill's enhancements pursued to codify collective happiness as the determinant of all moral action (Dodds \& Danforth, 2009), and in the United States Declaration of Independence, Jefferson well declared the three important rights which are right of life, liberty, and the pursuit of happiness. 
Similarly, customer happiness can be aligned with same definition, it is linked directly with the service delivery that can emphasize the three rights and that support the well-being. While establishing the importance of quantifying and understanding attributes that affect and deliver well-being, there is different considerable evolvement in measuring and clarifying how individuals or customers feel in a wide range of circumstances, particularly while investigating the field of psychology (Osgood, Suci, \& Tannenbaum, 1957) and while studying behavioral economics (Kahneman, Krueger, Schkade, Schwarz, \& Stone, 2004). Many methods that have been used, such as experience sampling and day reconstruction (Kahneman et al., 2004), are designed and based on self-reported and ways to assess happiness levels dependent on individual's memory and their perception, which can reduce reliability (Osgood et al., 1957).

In service delivery, customer happiness exceeds customer expectation, it is the process of studying carefully the customers' needs, attitude and behaviors, and researching the best way to wow their customers based on their profile and segmentation.

Earlier, customer relationship strategy was developed based on the model "design-build-sell" which summarizes the product-oriented strategy, however, nowadays it is being transformed to reflect the customer centricity strategy through the new model of "sell-build-redesign" (Raman, 2004).

The mass marketing is now considered outdated method to reach your customers, while it is being replaced to the one-to-one marketing approach. In general, the goal of the marketing campaign is to expand the customer database by approaching new customers. Given the expensive cost of attracting new customers, it makes more sense to develop more business with current customers (Raman, 2004). Recently, the focus of marketing is being shifted from the acquiring big range of customers to dive in each customer's needs. Measuring the market performance is changed from measuring market share to measuring the share of wallet. Through using the customer data, businesses extended the idea of just dealing with customers to sell products to establish a long-term relation with the customer that can allow companies to sell products with a memorable service experience (Rygielski, Wang, \& Yen, 2002). Figure 2 stated by Torrico(2010) can be considered as the holistic framework that the current paper aimed to research part of it. The mentioned framework was verified and contributed some analysis of the effect of happiness on customer satisfaction that has been tested in China, Japan that Thailand. According to (Torrico, 2010), happiness equally influences customer satisfaction. Torrico (2010) has clearly highlighted the need to test the theories on different markets and industries. 


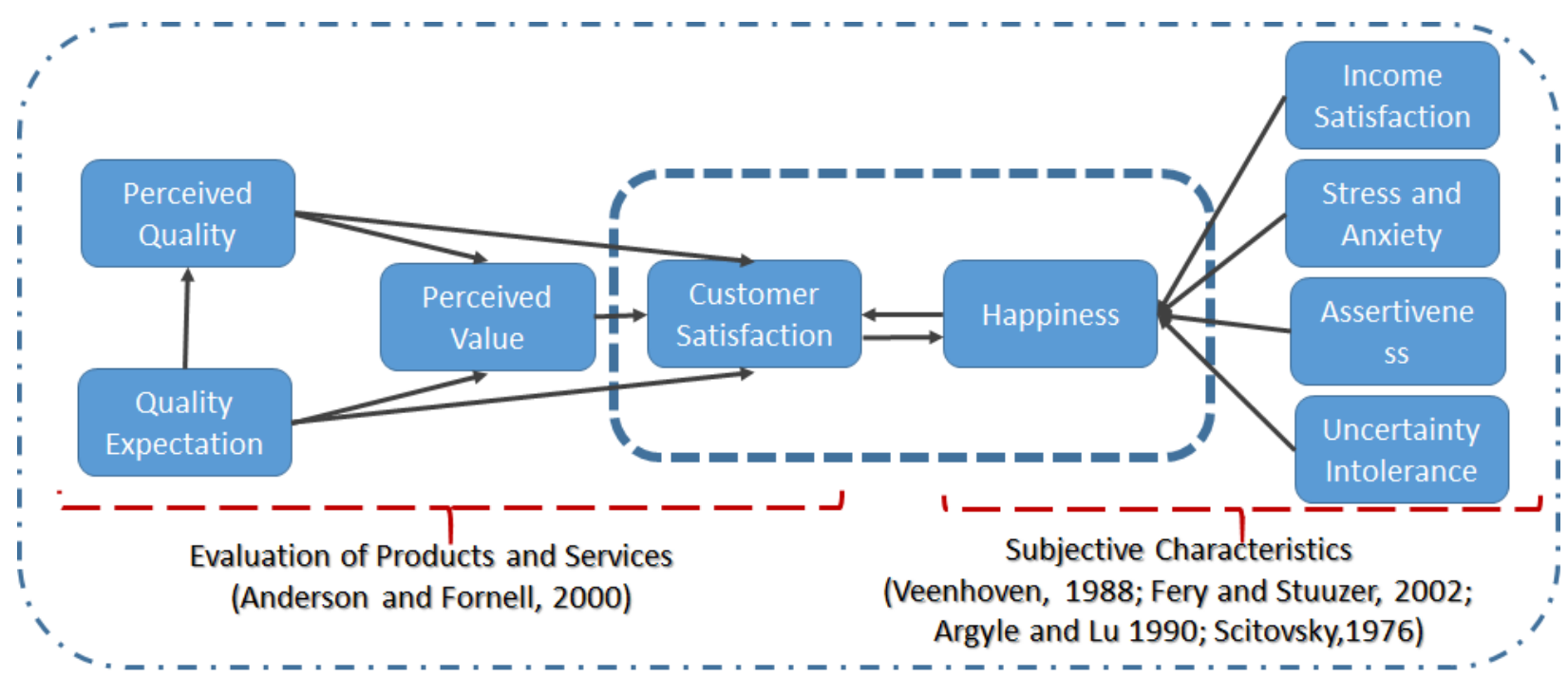

Figure 2. Research model and Hypothesis

UAE Government has taken a step towards exploring happiness by introducing related initiatives and programs for service delivery. One of the programs has changed all customer service charter to customer happiness formula, customer service employee to customer happiness ambassador, customer service center to customer happiness center, which principally emphasize on delivering excellence and exceeding customer expectation by understanding their needs and wowing customers.

National happiness is not a wish. Plans, projects, programs, and indices will be part of the mandate of all our ministries and our lifestyle. Based on such vision, UAE government has launched a comprehensive study to measure customer happiness, the target identified as UAE citizens and residents who has a direct transaction with UAE government in 2016.

In this study, the author proposed the happiness framework that helped the government to segment customers properly and identify key drivers that should be taken into consideration while designing a service or a product.

In a nutshell, the objectives of the study are to identify both internal and external factors that contribute on delivering happiness; to investigate and measure the customer experience of UAE citizens dealing with government services; to develop recommendation for enabling government entities to deliver happiness through delivering proper customer experience; and to recommend strategies to help companies and entities developing the best way in service delivery.

\section{Method}

\section{Research Design}

The research design discusses the overall strategy of this research to integrate the different components of the study. The research design consists of two phases:

Phase 1 refers to the qualitative study that will focus on identifying drivers of happiness for each customer segment while researching 202 nationalities receiving services in UAE. This will be conducted through a focus group that creates an accepting environment which puts customers at ease allowing them to attentively answer questions related to what can drive 
their happiness in their own words and add meaning to their answers. Later, a team will codify their answers and translate customer's own words into specific driver that can be prioritized and quantified in Phase 2. Each group has six to ten people led through twelve open-ended questions by a skilled moderator; each group has customers who share same demographics characteristics such as age group, gender, nationality, and social class. The interview guide consists of three types of questions: Engagement questions, which allow customers to be engaged on the discussion and break the ice; exploration questions, which open room for ideas and sharing thoughts related to happiness; and exit question, which is used to get more input from customers and conforming what mentioned earlier. During the analysis part, we looked into common categories or themes across the data for each question and then we arranged categories for those who repeated often during the discussion.

Phase 2 will follow with quantitative phase, which will be obtained through structured questionnaire where the focus will be mainly on collecting measurements related to each segment in order to quantify the state of happiness related to government services. Phase 2 will be carried out with multiple choices, rating scale based on 1-5 Likert scale which will help in analyzing results into three main categories, namely happy (using top two boxes), Neutral (middle box), and unhappy (bottom two boxes). To be cost efficient, we suggested to conduct the quantitative phase using face-to-face and telephonic interviews, and to sustain data accuracy and more insights from customers, we suggested running the survey using $60 \%$ face-to-face interviews and the other $40 \%$ will be telephonic interviews. Using majority of face-to-face interviews will also maintain capturing fresh experience and information that is more accurate. Sample of the questionnaire was tested and pre-tested in a small sample from one of government service centers to verify both reliability and scalability. The outcome of our research design is a structured questionnaire consisting of three main parts. The first part aimed to measure the level of agreement on the driver of happiness collected from Phase 1 as well as the importance for each driver; the second part focused to estimate customer satisfaction about the customer journey with the service including getting information, premises, employee's knowledge and professionalism, process and procedures, and payment and service delivery (Johnson \& Fornell, 1991); and the final part aimed to calculate the customer level of trust of the government and to measure customer perceived value compared to expected value (Chiou \& Droge, 2006). The new questionnaire with three main parts will be standard to use in measuring service happiness.

\section{Research Sample}

Samples are chosen to achieve minimum of 5\% margin of errors, which considered reasonable level of accuracy among studies in UAE and internationally (Berry \& Linoff, 2004). The qualitative study (Phase 1) consists of 50 focus groups taken from different segments in UAE (Citizens, Arab expatriates, Non-Arabs expatriates)

Different segments including male and female groups were covered, special groups were selected to cover the selective segments like the VIP's customers, elderly as well as special needs customers. In order to cover the emirates geographically, groups from different emirates were also part of the plan. Groups from all social classes and different education 
levels were also considered to confirm that the sample is statistically significant and representative to the current population of UAE.

Phase 1 was meant to understand the drivers of happiness, while the quantitative study (Phase 2) targeted sample size of 12000 customers who passed recently (last 3 months) with government service in emirates; sample will cover all mentioned segments. The research design is based on how structured is the approach, therefore, we will use structured approach in phase 2 which will quantify the happiness. Phase 1 will be unstructured and will research the driver of happiness.

\section{Research Framework (Hypothesis)}

Looking at different available frameworks that measures engagement and customer relationship, scholars emphasized the importance of measuring customer experience beyond purchase by designing framework that highlights the link between the behavioral part of the customer with the experience part (Vivek, Beatty, Dalela, \& Morgan, 2014). WHY5 framework was found to be very interesting, which build upon understanding customer identity, aspiration, and culture (Callebaut \&Novoseltev, 2016).

WHY5 is one of the research firms that has done extensive research on measuring happiness; they clearly differentiate between measuring happiness and satisfaction; they defined satisfaction using Cambridge dictionary as meeting expectation, being content, and being generally ok with service and to measure satisfaction; we need to measure the gap between performance Vs. expectation from services. While happiness can be considered by measuring the degree to which an individual benchmark generally the quality of his/her life happily, and this can be determined by focusing on measuring generally both quality of life and the well-being.

In fact, government services positively contribute to national happiness by helping to resolve existential day-to-day questions of people.

Figure 2 stats how government services can contribute in positioning people in community; in other words, understanding the physiological part of customer can help in understanding the best way to serve them. Figure 3 exhibits the existing day-to-day questions of people.

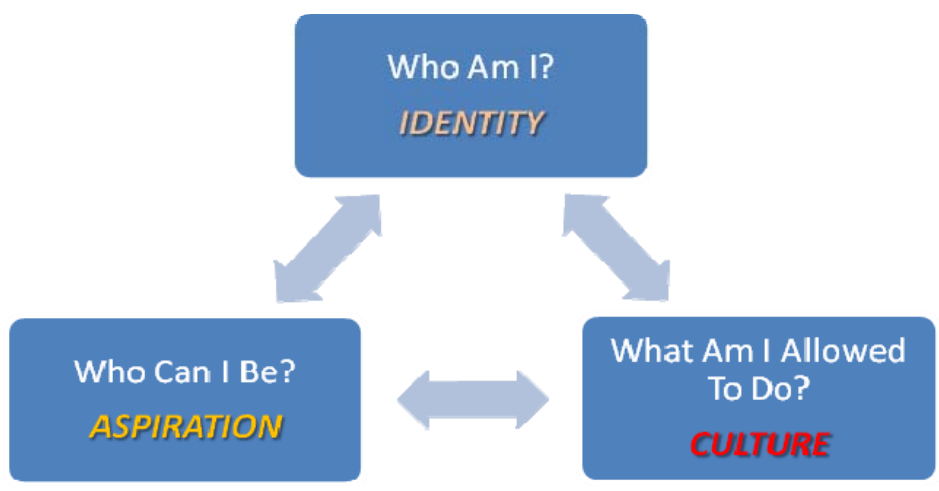

Figure 3. Existing day-to-day questions of people 
Accordingly, the key to identify people happiness is to identify drivers of happiness and this should be mapped on different customer segmentation. Figure 4 is the one introduced by WHY5 research to understand how people get happiness from life, meanwhile we have adopted same model, so that we can segment UAE customers on the same model (Callebaut \& Novoseltev, 2016).

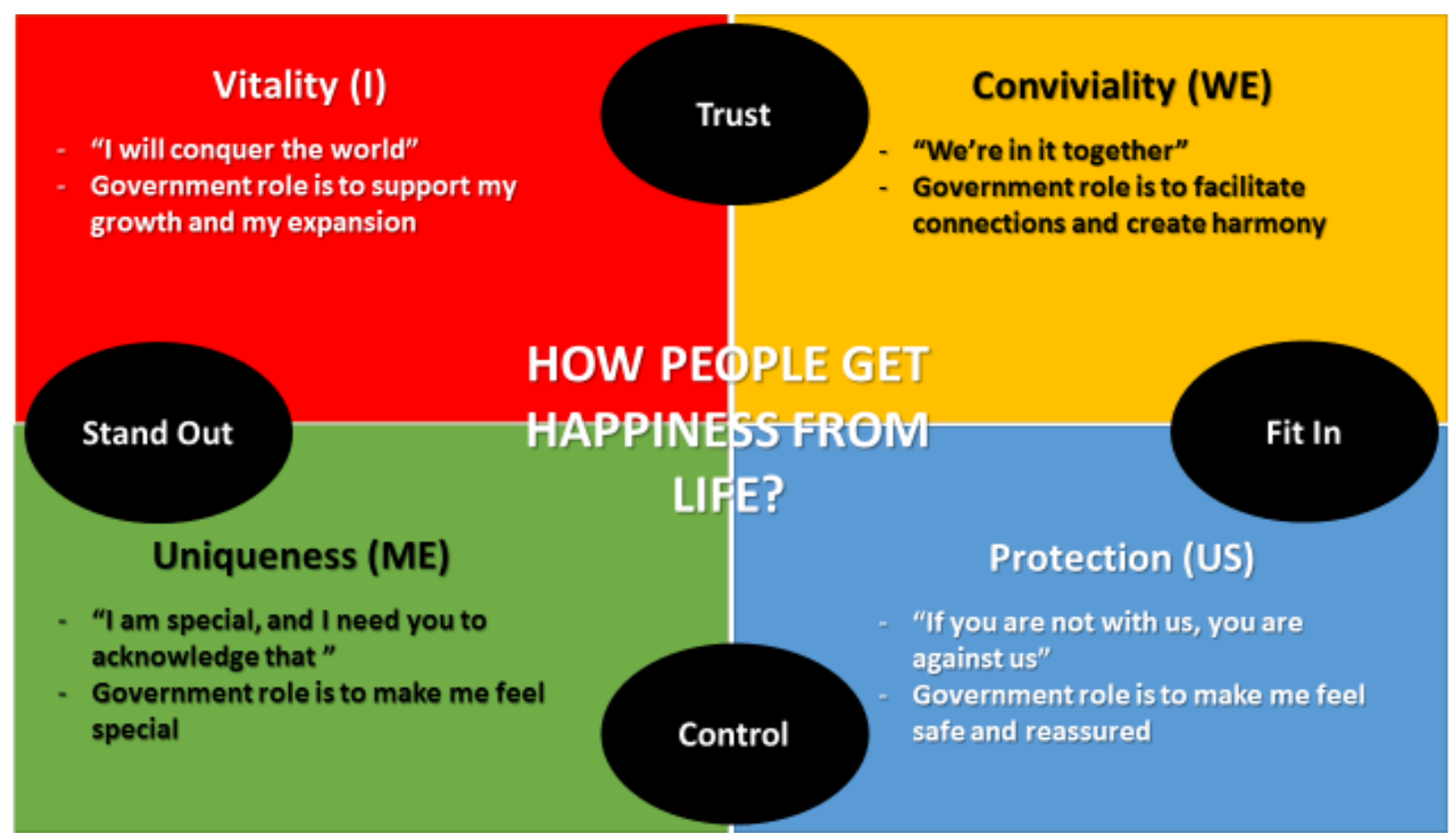

Figure 4. Happiness framework that has been used for customer segmentation

\section{Results}

The objectives of the study were identifying the drivers of happiness, which considered as the enabler to deliver service with happiness, and to define the contribution of each driver on each segment(that was done on December 2016); quantifying happiness and measuring the customer satisfaction score along with the customer happiness score; following these, the expected outcome of Phase 1 was to identify the drivers of happiness for each segment, to answer the question how to get happiness from life based on mentioned model. Almost 80 statements were the output of first focus group and then we prioritized the list using the two criteria, the frequency of repeating the statement during the discussion, and the weight of the statement as stated by customers, then we ended up with 16 statements that could represent the drivers for happiness for services in UAE. Figure 5 shows 16 statements mapped with the adopted framework, which will be guidance as well during the quantitative phase to segment customers properly. 


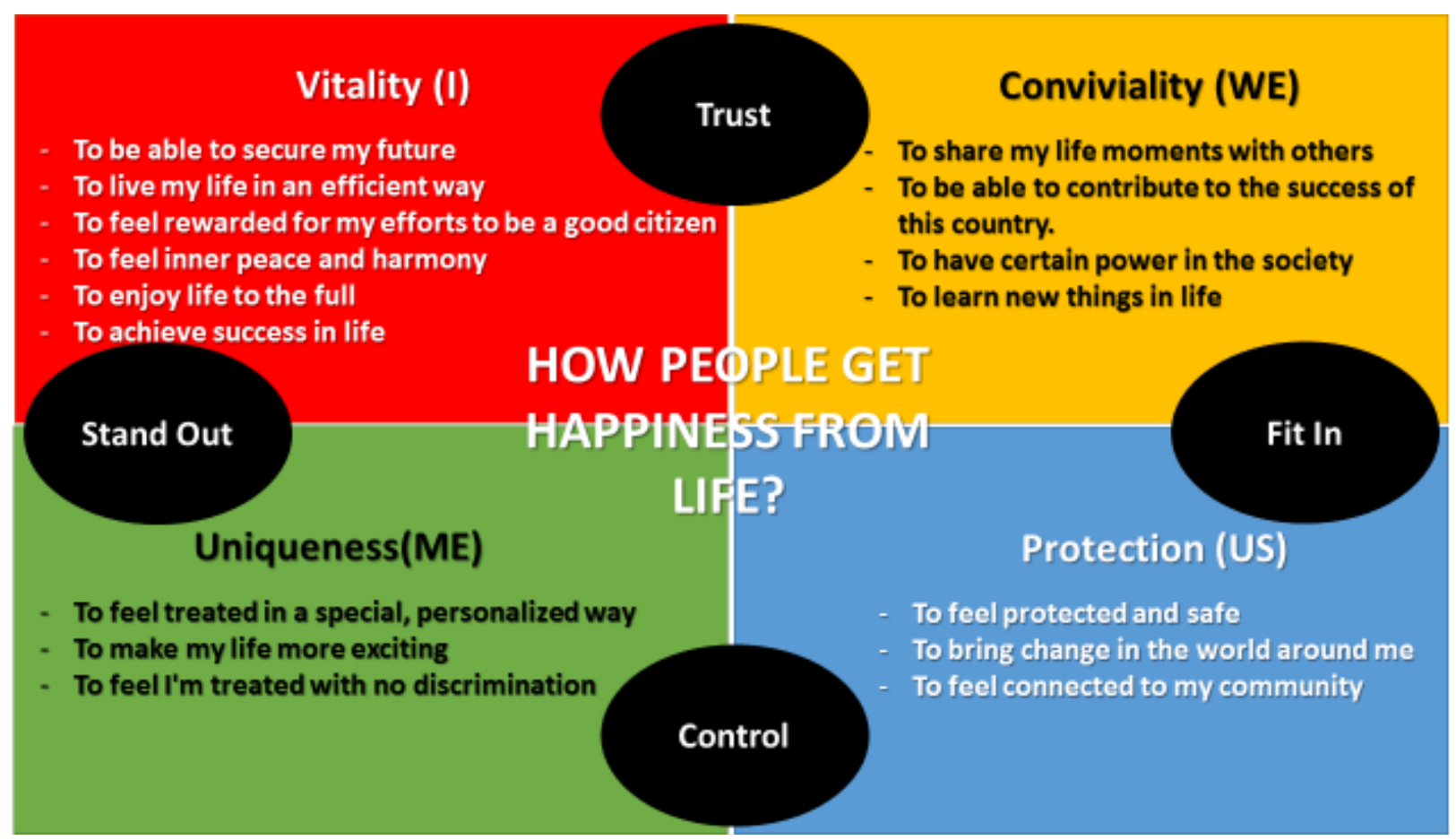

Figure 5. Drivers of happiness

\section{Discussion and Conclusion}

Above initial results and proposed framework represent how important is to pay full attention to studying customer happiness and the driver of happiness for each segment. Moreover, understanding the segment of the customer and what can make them happy will help in customizing services and products to meet not only their needs and satisfaction but also to build long lasting experience.

Due to the lack of the quantified part of the study, which is the validation part of the proposed model, we still can emphasize on four suggestions that we can consider as managerial implications:

- Organizations should consider the importance of developing happiness-driven experience rather than satisfaction-driven experience- this will help products to sustain the long lasting experience and will differentiate your products from others.

- The importance of segmenting customers and understanding what each segment will need and expect that you can build your service or product on that.

- UAE is scope of the study and is considered as a complicated market with 202 nationalities, however, it is important to test the theory in different markets, theoretically other markets will be easier especially for the case of homogenous population.

- The application of data mining will facilitate in generating analysis and non-trivial results in Phase 2.Data mining technique is expected to provide added value to verify the proposed framework. The use of predictive technique in data mining is intended to predict how to make customer happy based on existing data and pre-defined segmented customers (Kadiyala \& Srivastava, 2011). 
In this research, we have developed a unique questionnaire that is used as a template in UAE government and that can support the integration theory of the relation between both satisfaction and happiness. To test the model, we collected the data from UAE population with 202 nationalities coming from all over the world with different background and expectations and experiencing different government services. The paper consisted of a number of related work and research on the bidirectional effects and relationships between customer satisfaction and customer happiness.

Our initial qualitative results showed 16 drivers of happiness for the mentioned UAE government customers and also results emphasized that managers and business owners should understand that customer satisfaction not only depends on ordinary attributes such as service quality, perceived value, trust, employees, process, and procedures but also it depends on other factors like people happiness. Hence, increasing customer satisfaction scores could be also correlated to people happiness. Policy makers also should understand attributes that can affect people happiness and the reasons that can drive people consumption during certain circumstances like crises or recession (Helliwell, Huang, \&Wang, 2015).

Future research should focus on different markets and industries. It should also focus on the bidirectional relation between both happiness and effects and the correlation between both of the factors, which are linked to products and services evaluation and others, which are considered as subjective characteristics.

\section{References}

Anderson, E. W., Fornell, C., \& Lehmann., D. R. (1994). Customer satisfaction, market share, and profitability: Findings from Sweden. Journal of Marketing, 58(3), 53-66.

Berry, M. J., \& Linoff, G. S. (2004). Data mining techniques: For marketing, sales, and customer support. NY: New York: Wiley.

Callebaut, J., Bryssinck, J., Hellemans, V., Janssens, M., Meere, T., Novoseltsev, A., . . Gelder, E. V. (2011). Why you do what you do - A sensible guide in emotional (psychological) market research. why5research. Retrieved from http://www.why5research.com/: http://www.why5research.com/.

Chalmeta, R. (2006). Methodology for customer relationship management. The Journal of Systems \& Software, 79(7), 10151024.

Chiou, J. S., \& Droge, C. (2006). Service quality, trust, specific asset investment, and expertise: Direct and indirect effects in a satisfaction-loyalty framework . Journal of the Academy of Marketing Science, 34(4), 613-627.

Dodds, P. S., \& Danforth, C. M. (2009). Measuring the happiness of large-scale written expression: Songs, blogs, and presidents. Journal of Happiness Studies, 11(4), 441-456.

Gentile, C., Spiller, N., \& Noci, G. (2007). How to sustain the customer experience: An overview of experience components that co-create value with the customer. European Management Journal, 25(5), 395-410.

Greenberg, P. (2001). CRM at the speed of light: Capturing and keeping customers in internet real time. Berkeley, CA: Osborne/McGraw-Hill.

Helliwell, J., Huang, H., \& Wang, S. (2015). The geography of world happiness. In J. Helliwell, R. Layard, \& J. Sachs (Eds.), World happiness report, 2015 (pp. 2-11). New York: Columbia University Earth University.

Isen, A. M., Nygren, T. E., Taylor, P. J., \& Dulin, J. (1996). The influence of positive affect on the decision rule in risk situations: Focus on outcome (and especially avoidance of loss) rather than probability. Organizational Behavior \& Human Decision Processes, 66(1), 59-72.

Johnson, M. D., \& Fornell, C. (1991). A framework for comparing customer satisfaction across individuals and product categories. Journal of Economic Psychology, 12, 267-286.

Kadiyala, S. S., \& Srivastava, A. (2002). Data Mining For Customer Relationship Management. International Business \& Economics Research Journal (IBER), 1(6), 61-70. 
Kahneman, D., Krueger, A. B., Schkade, D., Schwarz, N, \& Stone, A. A. (2004). A survey method for characterizing daily life experience: The day reconstruction method. Science, 306(5702), 1776-1780.

Meyer, C., \& Schwager, A. (2007). Understanding customer expereince. Harvard Business Review, 85(2), 116-126.

Osgood, C. E., Suci, G. J., \& Tannenbaum, P. H. (1957). The measurement of meaning. Chicago: University of Illinois Press.

Raman, T. (2004). Knolwedge management: A resource book. New Delhi: Excel Books.

Rani, P. (2014). Factors influencing consumer behaviour. International Journal of Current Research \& Academic, 2(9), 5261.

Rygielski, C., Wang, J. C., \& Yen, D. C. (2002). Data mining techniques for customer relationship management. Technology in Society, 24, 483-502.

Shaw, C., \& Ivens, J. (2002). Building Great Customer Experiences. New York: Palgrave Macmillan.

Strauss, J., \& Frost, R. (2002). Customer relationship management. In J. Stauss \& R. Frost (Eds.), EMarketing (2 ${ }^{\text {nd }}$ ed.). Upper Saddle River, NJ: Prentice Hall.

Swinyard, W. R. (1993, September). The effects of mood, involvement, and quality of store experience on shopping intentions. Journal of Consumer Research, 20, 271-280.

Torrico, B. H. (2010). Analysis of the Effect of Happiness on Customer Satisfaction. ANQ Congress (pp. 1-10). Delhi: ResearchGate.

Verhoef, P. C., Lemonb, K. N., Parasuraman, A., Roggeveen, A., Tsiros, M., \& Schlesinger, L. A. (2009). Customer experience creation: Determinants, dynamics. Journal of Retailing, 85(1), 31-41.

Verhoef, P. C., Neslin, S. A., \& Vroomen, B. (2007). Multichannel customer management: Understanding the researchshopper phenomenon. International Journal of Research in Marketing, 24(2), 129-148.

Vermunt, R., Spaans, E., \& Zorge, F. (1989). Satisfaction, happiness and well-being of Dutch students. Social Indicators Research, 21, 1-33.

Vivek, S. D., Beatty, S. E., Dalela, V., \& Morgan, R. M. (2014). A generalized multidimensional scale for measuring customer engagement. Journal of Marketing Theory \& Practice, 22(4), 401-420. 